\title{
Editorial
}

\section{Ensino de Física: Reflexões}

Com este título foi realizado nos dias 11 e 12 de agosto do presente ano na Universidade de Brasília um encontro de físicos, educadores e representantes do governo para discutir a presente situação da educação científica no país, com foco no ensino de Física. O encontro foi promovido pelo MEC e SBF. Diversos problemas que afligem tanto a comunidade científica quanto o governo foram abordados em quatro mesas redondas cujos temas foram a formação de professores, a divulgação científica, a interdisciplinaridade e a educação a distância. De uma forma geral, esses quatro temas cobrem as discussões da pesquisa, do ensino e da popularização da Física.

Neste evento diferentes atores do cenário nacional de educação em Física puderam relatar suas realidades, apontar deficiências e acertos e discutir possíveis mudanças. A mesa "formação de professores" foi coordenada por Deise Miranda Vianna, secretária de ensino da SBF, tendo como debatedores Lucia Helena Lodi, do Departamento de Políticas de Ensino Médio do MEC, Oto Néri Borges (Coltec-UFMG), Susana de Sousa Barros (UFRJ) e Celso P. Melo (UFPE). Houve consenso entre os participantes da mesa quanto à grave crise no ensino de Física no Brasil que envolve, entre outros fatores, a formação de professores tanto na formação inicial quanto na formação continuada. A necessidade da modernização curricular para um ensino de qualidade bem como a pouca atenção dada aos resultados das pesquisas no modelo de formação profissional foram destacadas pelos debatedores. Foram realçadas sobremaneira a deficiência crônica de professores de Ensino Médio na área de Física e a questão da ociosidade do sistema tendo em vista a grande evasão nos cursos de Física. O sério risco de o país passar a ser um exportador de talentos foi aventado por Celso Melo.

A questão da divulgação da Ciência foi enfocada por Ildeu de Castro Moreira, do Departamento de Popularização e Difusão da Ciência e Tecnologia do MCT que apresentou as linhas gerais de uma política de popularização da C\&T e relatou as ações empreendidas pelo MCT nesta área com destaque para a realização anual da Semana de Ciência e Tecnologia. O coordenador da mesa, Ernst Hamburger (USP), apresentou um histórico das iniciativas no Brasil no terreno da divulgação científica. Antonio Carlos Pavão (UFPE) discorreu sobre a divulgação científica ao longo da história ocupando-se, ao final, do Espaço Ciência no Recife. Nelson Studart discutiu o papel das revistas de ensino na alfabetização científica, em particular, sua experiência à frente da revista Fúsica na Escola.

O tema da interdisciplinaridade no ensino nos vários níveis foi abordado por Beatriz Alvarenga da UFMG (Ensino Médio) e Leandro Tessler da Unicamp (ensino superior). Luis Davidovich, da Academia Brasileira de Ciências (ABC) e da UFRJ fez uma exposição sobre a proposta da $\mathrm{ABC}$ da reforma universitária do ensino superior em discussão no congresso nacional.

O significado da educação a distância e o emprego de novas tecnologias para a melhoria da educação foram avaliados em outra mesa redonda. Relatos de experiências com a educação a distância na área de Física foram apresentados por Ciclamio Leite Barreto (UFRN), José André Peres Angotti (UFSC), Silvio Luiz Sousa Cunha (UFRGS) e Carlos Eduardo Bielschowsky (UFRJ) sob a coordenação de Gil da Costa Marques (USP).

Durante o evento foi lançado o volume da coleção "Explorando o Ensino de Ciências - Física" que contém uma seleção de artigos de interesse para o professor de Ensino Médio, publicados após 2000 na Revista Brasileira de Ensino de Fúsica, na Fúsica na Escola e no Caderno Brasileiro de Ensino de Fúsica. A coleção editada pelo MEC, com tiragem de 72 mil exemplares, será distribuída em todas as escolas.

Os conselheiros Alfredo Gontijo de Oliveira e Rita Maria Cunha de Almeida e a secretária de ensino Deise Miranda Vianna foram designados pela SBF para apresentar um relatório final sobre o encontro e os principais pontos de destaque do documento-síntese estão apresentados a seguir.

\section{Responsabilidade do poder público}

Educação é um direito de cidadania e o Estado não pode abdicar dessa obrigação devendo estabelecer as condições para programas abrangentes de ensino nos níveis fundamental, médio e superior. Um grande desafio consiste em estabelecer políticas públicas que contemplem a diversidade do perfil sócio-econômicocultural da sociedade brasileira. Dessa forma, não se deve apelar para políticas padronizadoras. A questão da educação se relaciona diretamente com a questão da identidade nacional e será necessária uma política agressiva em educação para que, através de seu sucesso, consigamos assegurar a inclusão independente do Brasil no cenário de globalização.

\section{Continuidade}

Manter uma sistemática de continuidade dos pro- 
gramas, o que poderia ser assegurado através de instrumentos legais. A descontinuidade de programas se transforma em desperdício de esforço intelectual e de recursos financeiros.

\section{Ociosidade}

Existe ociosidade no sistema instalado e deveriam ser feitos esforços para reduzi-la e, até mesmo, eliminála, através de políticas de indução, gestão e modernização curricular.

\section{Papel das tecnologias da informação}

É bastante evidente que os novos instrumentos tecnológicos são cada vez mais relevantes na implementação de programa de ensino em qualquer escala e em modernos projetos acadêmicos pedagógicos. Essas ferramentas são, por exemplo, imprescindíveis em programas de ensino a distância. É importante que estejam presentes nos programas de ensino presenciais.

\section{Ensino a distância}

Embora esteja muito claro que ensino a distância não possa ser identificado como uma metodologia universal para resolver todos os problemas do sistema educacional, ele se apresenta como um poderoso instrumento de massificação, conseguindo atingir um número cada vez maior de alunos e que isso pode ser feito contemplando parâmetros de qualidade. Deve ser dada atenção ao desenvolvimento do aluno para que não haja evasão.

\section{Interdisciplinaridade e transdisciplinaridade}

A explosão do conhecimento tem forçado a abordar questões e problemas de forma temática, o que funciona como um estímulo a abordagens inter e transdisciplinares e levando a processos de formação que tratem ensino com maior diversidade. A flexibilização curricular é um instrumento que favorece essas abordagens.

\section{Financiamento}

É de responsabilidade do Estado a manutenção do sistema educacional, podendo, para isso, fazer concessões à iniciativa privada para viabilizar um programa abrangente de ensino. O sistema de avaliação e acompanhamento do projeto, nos seus aspectos genéricos, é de responsabilidade do poder público.

\section{Popularização da Ciência}

A complexidade da Ciência demanda esforços crescentes no sentido de manter a população minimamente educada para o pleno exercício da cidadania, sobre o significado da Ciência e suas implicações sobre a tecnologia.

\section{Formação de professores}

Existe um grande déficit de professores, em quantidade e qualidade. A reforma universitária de 1968 priorizou a constituição de quadros de pesquisadores nas universidades públicas. De fato, o mote da época era "precisamos formar uma geração de pesquisadores". Esse objetivo foi atingido e o mote agora precisa ser mudado para "precisamos formar uma geração de docentes universitários que, além de bons pesquisadores tenham também habilidade para as questões de ensino, sociais e nacionais". Esse deveria ser um caminho para resolver a questão de formação de professores, qual seja, a de desenvolver uma sensibilidade da questão junto ao quadro de atuais pesquisadores das universidades. A prática e o rigor científico podem agora ser transferidos para a questão de ensino de forma abrangente.

Espera-se que estas "reflexões" forneçam subsídios para a formulação de políticas públicas que contribuam para a melhoria da educação científica no Brasil.

O material utilizado pelos expositores, resenhas das apresentações e o documento-síntese estarão disponíveis no sítio da SBF. 